\title{
Strategies to Reform Engineering Education
}

\author{
Bharat Raj Pahari \\ Department of Civil Engineering Institute of Engineering, Tribhuvan University, Nepal \\ Corresponding email: brpahari@ioe.edu.np
}

\begin{abstract}
After the globalization, the attention of the world is turning to economy. The world power is shifted to economy. There has been a paradigm shift- the physical resources; such as, minerals, lands, etc. as the property, has changed. The world is expanding to a global village and societies are heading towards knowledge base economy. By now, a country cannot survive in a closed boundary as before. The result of this is obviously cognitive revolution along with the continuous innovation. Above this, the effect of globalization is turning the world to the international partnerships diversifying the workforce and resulting to demographic shifts. The education, more precisely the engineering higher education, should be able to load individual the depth knowledge and skill that makes people capable and competent. In the course of time, the role of engineering education is increasing. This article is shedding light on the strategies for the reform of engineering education in Nepal eventually attaining quality.
\end{abstract}

\section{Introduction}

Over the past two decades, the engineering higher education system in Nepal has successfully concentrated on production of engineers and on developing infrastructures for engineering higher education. The first batch of engineers enrolled were 22 in Institute of Engineering and passed numbers were 17 in 1983 and this has increased to about 2014 in 2003 (IOE, 2005 \&UGC, 2004) annual intake from 28 engineering colleges so far. However, there are the voices from policy makers, employers and faculties that the existing level of graduating engineers from Nepal are not meeting the standard demanded by the market (Shrestha, 2006). In the course of time, pressure has been intensified to respond this in prevailing education system. This has developed concern over the equity, quality and competence in engineering higher education. Moreover, the effect of globalisation is now appearing in Nepal. The quality and competence are the prime issues now. Unless, Nepalese engineers prove to be capable and competence in the global market, the situation is going to be much harder for them now and after (Paudel, 2006).

\section{The Strategies and the Respondents}

A study was conducted to identify the strategies to reform engineering higher education in Nepal. After going through extensive literature review, some 99 statements related to the strategies to reform engineering education were identified. These statements were grouped into nine major categories. These categories were related to; financing in Engineering Education, Faculties and Their Role, Equity and Access, Management and Institutional Development, Students and Their Activities, Socio-Cultural Imperatives, Infrastructure strategies, Curriculum and Assessment System, Job Market and Its Reality. 
The respondents were identified as the policy makers, faculties, students and employers. The opinions of the respondents were taken as the basis to identify the strategies to reform engineering higher education in Nepal. The respondents were asked to rate 99 statements related to the reform strategies for quality of engineering education.

\section{The Rating on the Strategies}

The rating of the respondents for each statement on reform strategies to resolve issues influencing quality of engineering higher education was entered in to the table. In the table almost all respondents rated fair to good to the statement for strategies. The rating of the sum of the statements in the categories as derived by SPSS program is presented in the table below;

Rating of the Reform Strategies for Engineering Education

\begin{tabular}{lrrrrrrr}
\hline \multicolumn{1}{c}{ Strategies } & NA & SD & D & ND & A & SA & Total \\
\hline S-1 Financing in Engineering Education & 1 & 1 & 4 & 17 & 47 & 31 & 100 \\
S-2 Faculties and Their Role & 0 & 0 & 2 & 7 & 51 & 40 & 100 \\
S-3 Equity and Access & 1 & 1 & 3 & 15 & 47 & 32 & 100 \\
S-4 Mgmt and Institutional Development & 0 & 0 & 2 & 11 & 52 & 35 & 100 \\
S-5 Students and Their Activities & 0 & 0 & 2 & 12 & 49 & 37 & 100 \\
S-6 Socio-Cultural Imperatives & 1 & 2 & 3 & 15 & 52 & 27 & 100 \\
S-7 Infrastructure Strategy & 0 & 0 & 2 & 13 & 50 & 35 & 100 \\
S-8 Curriculum and Assessment System & 0 & 0 & 1 & 11 & 53 & 34 & 100 \\
S-9 Job Market and Its Reality & 0 & 0 & 1 & 7 & 46 & 45 & 100 \\
\hline
\end{tabular}

(NA-not applicable, SD-strongly disagree, D-disagree, ND-not disagree, A-agree, SA- strongly agree)

The data presented in the table showed the respondents perceptions concerning financial strategies for engineering education. The data indicated that respondents considered the financial strategy a governing component for the quality of engineering education. Data showed that 78 percent of the respondents either strongly agreed or agreed the financial aspect as the major strategy to attain quality of engineering education. Among the respondents, 17 percent were neutral in this strategy and 4 percent respondents disagreed financing as a reform strategy, 1 percent strongly disagreed and 1 percent opined as not applicable.

In the table, respondents had divided opinions regarding faculties and their role as the reform strategy to attain quality of engineering education. Among the respondents, 91 percent strongly agreed or agreed on the faculties and their role as a strategy for quality of engineering education, whereas, 7 percent were neutral, 2 percent disagreed.

The data in the table showed the respondents perceptions concerning equity and access strategy for quality of engineering education. The rating indicated that respondents considered the equity and access as a governing component for the quality of engineering education. Data showed that 79 percent of the respondents either strongly agreed or agreed the equity and access as the major strategy to attain quality of engineering education. 15 percent of the respondents were neutral in this strategy and 3 percent respondents disagreed, 1 percent strongly disagreed on the strategy.

The table showed the respondents perceptions concerning the strategy for management and institutional development to attain the quality of engineering education. The data indicated that 
respondents considered the management and institutional barrier as a governing component for the quality of engineering education. Data showed that 87 percent of the respondents either strongly agreed or agreed the management and institutional development as the major strategy to attain quality of engineering education. 11 percent of the respondents were neutral in this strategy and 2 percent respondents disagreed.

The table presented the respondents perceptions concerning strategy for students and their activities to attain quality of engineering education. The data indicated that respondents considered the students and their activities as a governing component for the quality of engineering education. Data showed that 86 percent of the respondents either strongly agreed or agreed students and their activities as the major strategy to attain quality of engineering education. 12 percent of the respondents were neutral in this strategy and 2 percent respondents disagreed.

The data in the table showed the respondents perceptions concerning strategy for socio-cultural imperatives to attain quality of engineering education. The data indicated that respondents considered the socio-cultural imperatives as a governing component for the quality of engineering education. Data showed that 79 percent of the respondents either strongly agreed or agreed the socio-cultural imperatives as the major strategy to attain quality of engineering education. 15 percent of the respondents were neutral in this strategy and 3 percent respondents disagreed, 2 percent strongly disagreed and 1 percent opined as not applicable.

The table showed the respondents perceptions concerning infrastructure strategy to attain quality of engineering education. The data indicated that respondents considered the infrastructure strategy as a governing component for the quality of engineering education. Data showed that 85 percent of the respondents either strongly agreed or agreed the infrastructure strategy as the major strategy to attain quality of engineering education. 13 percent of the respondents were neutral in this strategy and 2 percent respondents disagreed.

The data in the table showed the respondents perceptions concerning curriculum and assessment system to attain quality of engineering education. The data indicated that respondents considered the curriculum and assessment system as a governing component for the quality of engineering education. Data showed that 87 percent of the respondents either strongly agreed or agreed the curriculum and assessment system as the major strategy in influencing engineering education. 11 percent of the respondents were neutral in this strategy and 1 percent respondents disagreed.

The rating in the table showed the respondents perceptions concerning job-market strategy to attain the quality of engineering education. The data indicated that respondents considered the job-market strategy as a governing component for the quality of engineering education. Data showed that 91 percent of the respondents either strongly agreed or agreed the job-market issue as the major strategy to attain quality of engineering education. 7 percent of the respondents were neutral in this strategy and 1 percent respondents disagreed. 


\section{Respondents Rating on Strategies}

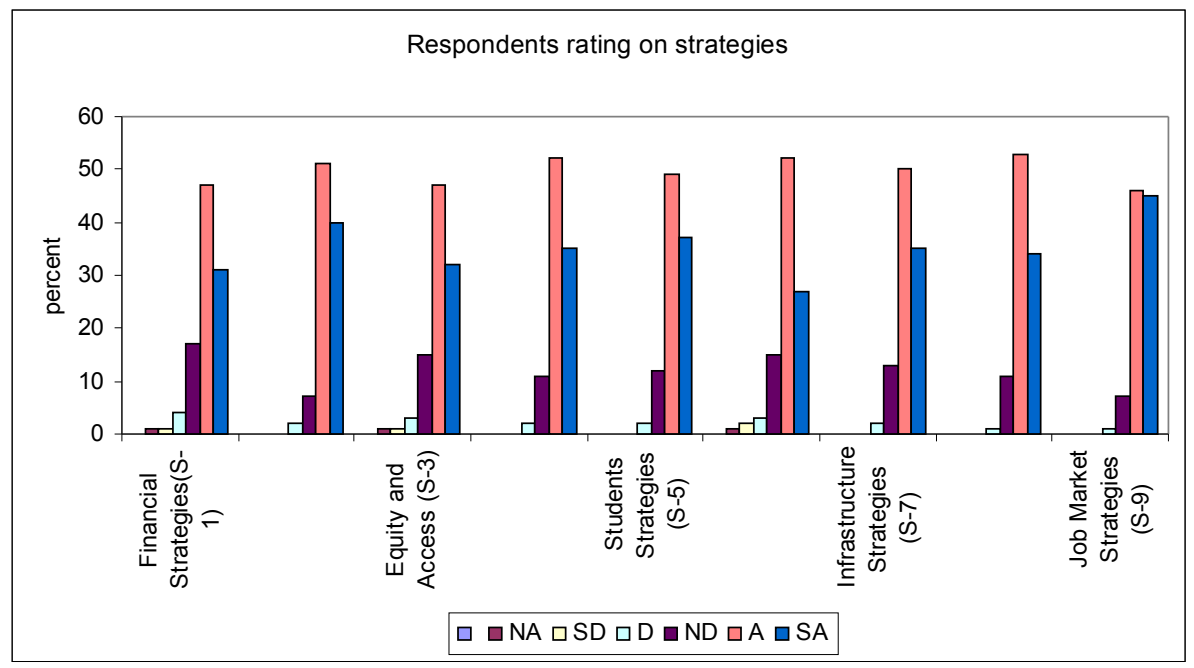

The rating of the respondents on the strategies is illustrated in the histogram, such that those identified strategies are overwhelmingly accepted by the respondents.

\section{Other strategies}

The respondents had also marked some of the strategies in the space left for respondents' opinion in the open ended question part. Not all the respondents responded in this part. The open ended questions were very much valuable to find other prominent strategies from the responses of the respondents. Initially 25 numbers of samples were manually noted and verified. The substantial majority of the responses (76 percent) indicated the other prominent strategies as; politicization, research and development and policy strategy. The ratings of these strategies are illustrated in the figure below;

Other strategies to attain quality of engineering education 


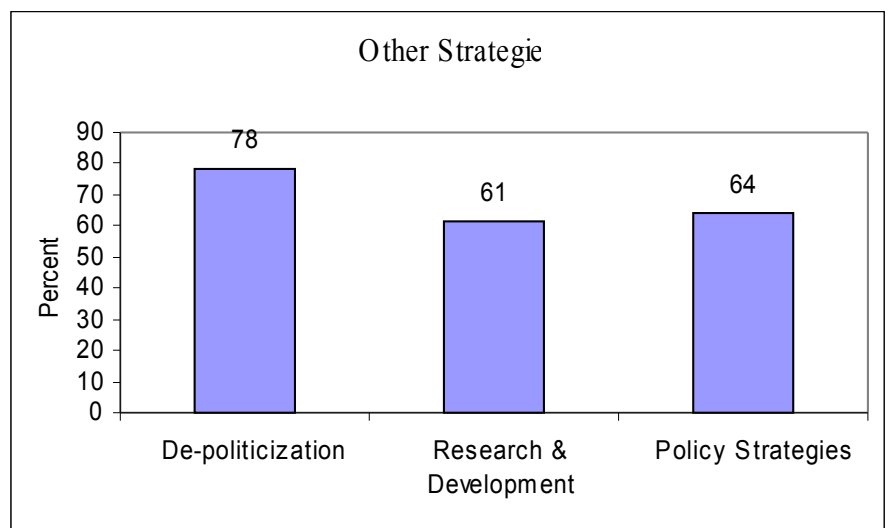

Following the figure, large numbers of respondents (78 percent) responded that strategy should be made for de-politicization in the engineering education system to attain quality of engineering education. They indicated that the students, faculties and staffs are all politicizing to satisfy their vested interest and quality is left in the second priority. Some of the respondents (61 percent) gave the opinion that strategy should be made for research and development in the institution to attain quality of engineering education. Sufficient numbers of respondents (64 percent) gave the opinion that the policy strategy is responsible for the quality of engineering education.

\section{Analysis of the Responses}

The analysis was done of mean values of responses. The table below gives the detail picture of all categories of strategies to resolve issues influencing engineering education.

\begin{tabular}{|l|r|r|r|r|}
\hline \multicolumn{1}{|c|}{ Strategies } & Faculty & \multicolumn{1}{c|}{ Student } & \multicolumn{1}{c|}{$\begin{array}{c}\text { Policy } \\
\text { Maker }\end{array}$} & \multicolumn{1}{c|}{ Employers } \\
\hline S-1 Financing in Engineering Education & 36.86 & 36.68 & 38.03 & 38.79 \\
\hline S-2 Faculties and Their Role & 39.16 & 37.74 & 39.63 & 39.09 \\
\hline S-3 Equity and Access & 36.69 & 35.84 & 35.56 & 37.48 \\
\hline S-4 Mgmt and Institutional Development & 42.45 & 41.40 & 42.78 & 42.64 \\
\hline S-5 Students and Their Activities & 45.16 & 46.68 & 44.53 & 47.00 \\
\hline S-6 Socio-Cultural Imperatives & 39.98 & 39.40 & 40.31 & 41.39 \\
\hline S-7 Infrastructure Strategy & 47.61 & 46.91 & 46.91 & 47.24 \\
\hline S-8 Curriculum and Assessment System & 82.90 & 83.49 & 84.03 & 86.12 \\
\hline S-9 Job Market and Its Reality & 43.84 & 42.98 & 43.59 & 44.58 \\
\hline
\end{tabular}

The table presented the mean values of the responses. The mean values of the responses of faculty and students for financing strategy are found similar, and also the policy makers and employers opinions are similar. Policy makers and employer ranked higher in compare to others. On the strategy for faculties and their role, employers, policy makers and faculties have rated 
higher to the students. The student rated slightly lower to the strategy related with faculties and their role. Students and policy makers rated slightly lower to the strategy for equity and access, whereas, faculty and employer rated higher. The students have rated lower to the strategy for management and institutional development. The students and employer rated higher to the strategy for students and their activities compared to the policy makers and faculty. The employers and policy makers rated slightly higher to others to strategy for socio-cultural imperatives. All the respondents rated more or less in the same level to the strategy for infrastructure. Students and faculties rated lower and policy makers and employers emphasized more to the strategy for curriculum and assessment system. The employer marked more to the job-market strategy to attain the quality.

The deviations in the mean values were further analyzed with the help of analysis of variance (ANOVA). This was used to determine if there are significant differences in the perceptions among the responding groups for 99 statements in four categories (refer appendix-ii) included in the questionnaire. The details of the ANOVA for 99 statements for existing level are included in the appendix-xii. The level of significance of each statement and of categories was found through this analysis. Visualizing the each statement in the ANOVA table included in the appendix-xii, the perceptions of the respondents were not found significantly different.

As stated earlier, the strategy statements were grouped in nine categories. Among them, financing, faculty and equity $\&$ access categories contained 9 statements, management, sociocultural imperatives and job-market strategy categories contained 10 statements, students and infrastructure categories contained 11 statements and curriculum and assessment system contained 20 statements (refer appendix-ii). The responses were further analysed in the categories as well. The summary ANOVA for each of nine categories regarding level of agreements is shown in the table below.

ANOVA Table for Strategy for Financing in Engineering Education

\begin{tabular}{|c|c|c|c|c|c|c|}
\hline Strategies & & $\begin{array}{l}\text { Sum of } \\
\text { Squares }\end{array}$ & df & $\begin{array}{l}\text { Mean } \\
\text { Square }\end{array}$ & $\mathrm{F}$ & $\begin{array}{l}\text { Level of } \\
\text { Sig. }\end{array}$ \\
\hline \multirow[t]{3}{*}{ s1_sum } & Between Groups & 133.5 & 3.0 & 44.5 & 1.329 & 0.266 \\
\hline & Within Groups & $7,431.3$ & 242.0 & 33.5 & & \\
\hline & Total & $7,564.8$ & 245.0 & & & \\
\hline \multirow[t]{3}{*}{ s2_sum } & Between Groups & 137.7 & 3.0 & 45.9 & 2.427 & 0.066 \\
\hline & Within Groups & $4,196.8$ & 242.0 & 18.9 & & \\
\hline & Total & $4,334.5$ & 245.0 & & & \\
\hline \multirow[t]{3}{*}{ s3_sum } & Between Groups & 80.3 & 3.0 & 26.8 & 0.996 & 0.396 \\
\hline & Within Groups & $5,965.0$ & 242.0 & 26.9 & & \\
\hline & Total & $6,045.2$ & 245.0 & & & \\
\hline \multirow[t]{3}{*}{ s4_sum } & Between Groups & 77.3 & 3.0 & 25.8 & 1.093 & 0.353 \\
\hline & Within Groups & $5,234.5$ & 242.0 & 23.6 & & \\
\hline & Total & $5,311.8$ & 245.0 & & & \\
\hline \multirow[t]{3}{*}{ s5_sum } & Between Groups & 152.5 & 3.0 & 50.8 & 2.054 & 0.107 \\
\hline & Within Groups & $5,494.5$ & 242.0 & 24.7 & & \\
\hline & Total & $5,647.0$ & 245.0 & & & \\
\hline
\end{tabular}




\begin{tabular}{llrrrrr} 
s6_sum & Between Groups & 87.6 & 3.0 & 29.2 & 0.941 & 0.422 \\
& Within Groups & $6,895.0$ & 242.0 & 31.1 & & \\
& Total & $6,982.6$ & 245.0 & & & \\
s7_sum & Between Groups & 22.8 & 3.0 & 7.6 & 0.203 & 0.894 \\
& Within Groups & $8,294.2$ & 242.0 & 37.4 & & \\
& Total & $8,317.0$ & 245.0 & & & \\
s8_sum & Between Groups & 138.5 & 3.0 & 46.2 & 0.659 & 0.578 \\
& Within Groups & $15,542.5$ & 242.0 & 70.0 & & \\
\multirow{3}{*}{ s9_sum } & Total & $15,680.9$ & 245.0 & & & \\
& Between Groups & 59.8 & 3.0 & 19.9 & 0.915 & 0.434 \\
& Within Groups & $4,837.9$ & 242.0 & 21.8 & & \\
& Total & $4,897.8$ & 245.0 & & & \\
\hline
\end{tabular}

Above ANOVA table has given the values of level of significance between the opinions of the respondents on strategies to resolve issues influencing the quality of engineering education under nine categories. Considering the level of significance by 5 percent, any group that has level of significance less than 0.05 is accepted as significant difference of opinion and needs for further Scheffe's multiple comparison test. In the table 44, all the nine groups- S1, S2, S3, S4, S5, S6, S7, S8 and S9 have level of significance-0.266, 0.066, 0.396, 0.353, 0.107, 0.422, 0.894, 0.578 and 0.434 respectively. Therefore, there exists no significant difference in the perception of respondents in all nine categories.

\section{Ranking of Reform Strategies}

Analysis of variance for each of the 99 strategy statements in nine categories was calculated to determine whether there are statistically significant differences in the perceptions of respondents - faculty, student, policy maker and employer. Following the 5 point Likert rating, the ranks of responses ( 4 \& 5) above average (3) are marked in the high range. Those ranked on the good (3) level (the average) is marked as middle and those ranked (NA, $1 \& 2$ ) below the average (3) are marked in low range. The ranking of the respondents on the statements concerning strategies is included in the appendix-xi. According to the table, overwhelming responses are to the higher side establishing the statements to be true.

\section{Most Prominent Reform Strategies}

Following the five point Likert rating, ranking was made in such a way that those statements with; not applicable, poor and fair $(\mathrm{N}, 1 \& 2)$ were marked as low. Others with good level (3) were marked as middle and those statements with; very good and excellent levels $(4 \& 5)$ were marked as high level. The statements with middle marking were not included in the table as they do not influence the analysis. In the table, percentages of frequencies are taken for the analysis.

Most prominent issue statements were found from the descriptive statistical analysis. Following tables give picture of highest ranking of reform strategy statements.

Ranking of Financial Strategy

\begin{tabular}{ccc}
\hline Items & High percent & Low percent \\
\hline S1 & 73.0 & 8.3
\end{tabular}




$\begin{array}{llc}\text { S2 } & 88.3 & 0.4 \\ \text { S3 } & 93.9 & 1.3 \\ \text { S4 } & 89.6 & 0.9 \\ \text { S5 } & 63.9 & 14.8 \\ \text { S6 } & 81.7 & 3.0 \\ \text { S7 } & 80.0 & 5.2 \\ \text { S8 } & 87.4 & 2.6 \\ \text { S9 } & 79.1 & 7.4\end{array}$

There were nine strategy statements in financing strategy. Some of those strategies were highly supported by respondents and others were not given priority. Data in the above table showed that almost all of those strategy statements were highly supported by respondents. All the respondents had given high priority to the financing strategy. The mathematical ranking of distinction ( 80 percent and above), as the outstanding ranking, has been taken as the basis of marking prominent strategy. Following this benchmark, six statements were found standing in this ranking in the financing category.

Those statements in highest priorities are as follows: Allocate appropriate budget for research and innovation, Allocate appropriate budget for new technologies, Minimize wastage, optimize overheads and encourage efficient and effective use of resources, Establish cost control measures with transparent \& effective financial management, Explore and initiate to find resources and funding from business and industry for academic programs and research in engineering education, Explore and initiate to find resources and funding from private sector for development and expansion of engineering education, etc.

\begin{tabular}{ccc}
\multicolumn{3}{c}{ Ranking of Strategy for Faculty } \\
\hline Items & High percent & Low percent \\
\hline S10 & 90.9 & 0.9 \\
S11 & 90.9 & 2.2 \\
S12 & 93.9 & 1.3 \\
S13 & 90.9 & 2.2 \\
S14 & 90.9 & 2.2 \\
S15 & 92.2 & 2.2 \\
S16 & 88.7 & 2.2 \\
S17 & 87.0 & 2.2 \\
S18 & 88.7 & 2.6
\end{tabular}

There were nine strategy statements in strategy of faculties and their role. Data in the above table showed that almost all of those strategy statements were highly supported by respondents. All the respondents had given high priority to the strategy of faculties and their role. The mathematical ranking of distinction ( 80 percent and above), as the outstanding ranking, has been taken as the basis of marking prominent strategy. Following this benchmark, all the statements have scored more than 80 percent. Among them, six of the statements scored more than 90 percent. 
Those statements in highest priorities are as follows: Start and establish dynamic teaching and research process in higher engineering education, Establish system of continuing professional development of faculties, Support and encourage participation of faculties in regional conferences, workshops and electronic conferences, Provide internet facilities and encouraging publications over internet, Develop institutional set-up, formulate comprehensive guidelines and conduct transparent procedures of faculties' recruitment. Develop, implement, and assess new instructional models, materials, and learning environments. Encourage faculties for Joint research or design projects within college and with other stakeholders, Develop a teacher management system that includes teacher education and training and conditions of service (appointment, deployment, transfer, salaries and benefits, career path etc.), Ensure technical competency of faculties that includes all requirement for certification and credentialing, evaluation includes; technical competency, instructional competency/certification, and technical updating, Motivate the faculties in the job by involving in continuing education program, consultancy services, and research projects, thus encouraging for additional remuneration. Prepare next generation of faculty and professionals wishing to pursue work in the field of engineering education, Coordinate and facilitate discussions to maintain the required quality standards of faculties, Set, maintain and control the quality standards of faculties, etc.

\begin{tabular}{ccc}
\multicolumn{3}{c}{ Ranking of Strategy for Equity \& Access } \\
\hline Items & High percent & Low percent \\
\hline S19 & 77.4 & 4.3 \\
S20 & 61.7 & 11.3 \\
S21 & 83.0 & 3.9 \\
S22 & 90.0 & 2.2 \\
S23 & 79.1 & 8.3 \\
S24 & 75.2 & 4.3 \\
S25 & 83.5 & 4.8 \\
S26 & 83.9 & 5.2 \\
S27 & 78.7 & 6.1 \\
\hline
\end{tabular}

There were nine strategy statements in strategy of equity and access. Data in the above table showed that some of those strategies were highly supported by respondents and others were not given priority. The mathematical ranking of distinction ( 80 percent and above), as the outstanding ranking, has been taken as the basis of marking prominent strategies. Following this benchmark, four of the statements have scored more than 80 percent.

Those statements in highest priorities are as follows: Encourage government for financial assistance, manage financial assistance by reliable organizations to needy students, Develop financing model with bank loan facilities and target subsidies to poor and needy students with a focus on reducing inequalities, discouraging inefficiencies and encouraging incentives for positive innovation and generation of additional resources, Start supporting programs for students from marginalized areas in pre-engineering level for building their capacity to compete in entry level of higher engineering education, Formulate the guidelines and processes to distribute scholarship to meritorious and needy students through the participation of stakeholders (students, faculties), Organize a system of selecting bright students from different regions in the scholarship scheme in the engineering education, etc. 


\begin{tabular}{ccc}
\multicolumn{3}{c}{ Ranking of Management Strategy } \\
\hline Items & High percent & Low percent \\
\hline S28 & 82.6 & 2.2 \\
S29 & 83.9 & 2.2 \\
S30 & 87.0 & 3.0 \\
S31 & 87.0 & 1.3 \\
S32 & 92.2 & 0.9 \\
S33 & 88.7 & 1.7 \\
S34 & 83.5 & 3.9 \\
S35 & 83.9 & 2.6 \\
S36 & 90.9 & 2.6 \\
S37 & 90.4 & 1.3 \\
\hline
\end{tabular}

There were ten strategy statements in strategy of management and the institutional development. Data in the above table showed that almost all of those strategies were highly supported by respondents. All the respondents had given high priority to the strategy of management. The mathematical ranking of distinction ( 80 percent and above), as the outstanding ranking, has been taken as the basis of marking prominent strategies. Following this benchmark, all the statements have scored more than 80 percent. Among them, three of the statements scored more than 90 percent.

Those statements in highest priorities are as follows: Conduct periodic meetings of all departments, committees and centres and arrange discussions on issues, challenges and programs, Develop norms and regulations to guide the behaviours of the management, faculties and staffs and avoid ad-hoc decisions, Simplify the methods of management and maintenance and make it output oriented, optimize the utilization of available space and equipment, make mandatory the periodic performance audit of campuses, Ensure dynamic and visionary leadership in all level of administration, Establish mechanism to entertain advices and guidance in design, development, operation, evaluation initiatives in the institution from; former deans, assistant deans, campus chiefs; senior professors and educational experts, Ensure and monitor routine works of the institutions, such as; conduction of defined meetings, recruitment practices, compliance with audit observation, academic monitoring, public information etc.(as important job of heads-Deans, principals/campus-chiefs, HOD etc.), Formulate detail job description for all level of management of staffs and ensure their role, responsibility, authority and accountability in the institution, provide an added mechanism of accountability of the process, through public disclosures of its progress, Identify and Chuck-out dysfunctional components in the engineering institution. Ensure financial, academic and management authority in the autonomy of institution, such as; appointment of staff on contract, term extension of contract faculties, staff selection appointment and dismissal, acceptance of resignation, frame policies and regulations on academic and administrative affairs, formulate financial regulations etc. Ensure dedicated and more concerned stakeholders (faculties, students, parents, industry, politicians, policy makers etc.) in management \& development council/ authorities; in the engineering institutions, etc.

Ranking of Strategy for Students

\begin{tabular}{ccc}
\hline Items & High percent & Low percent \\
\hline S38 & 92.2 & 1.3
\end{tabular}




$\begin{array}{lll}\text { S39 } & 90.0 & 2.6 \\ \text { S40 } & 91.3 & 1.3 \\ \text { S41 } & 92.2 & 0.4 \\ \text { S42 } & 85.2 & 0.9 \\ \text { S43 } & 81.3 & 3.0 \\ \text { S44 } & 73.0 & 5.7 \\ \text { S45 } & 87.4 & 2.2 \\ \text { S46 } & 87.0 & 0.4 \\ \text { S47 } & 85.2 & 3.9 \\ \text { S48 } & 77.8 & 4.3\end{array}$

There were eleven strategy statements in strategy of students and their activities. Data showed that some of those strategies were highly supported by respondents and others were not given priority. The mathematical ranking of distinction ( 80 percent and above), as the outstanding ranking, has been taken as the basis of marking prominent strategies. Following this benchmark, nine of the statements have scored more than 80 percent.

Those statements in highest priorities are as follows: Encourage academic and professional key skills, such as; publications of journals, new-letters web etc, interpersonal team working, presentation skill and ICT skills, Orient students for; well prepared to be leading engineers, as well as researchers, with a clear understanding of the strategic value of their area, Establish a system of Meaningful Career Counselling/social/emotional counselling mechanism. Encourage student led performances as a part of curricula, co-curricula and extra-curricula activities. Ensure supports (financial and academic guidance) for students' project works, Develop relevant programs to address students' mobility, Ensure availability of resource personnel to provide career guidance services, Fix Minimum \& maximum fee structure in cost basis for quality improvement, formulate proper scholarship scheme and introduce education loan. Support the students' activities concerning their rights and values, etc.

Strategy for Social-cultural Imperatives

\begin{tabular}{ccc}
\hline Items & High percent & Low percent \\
\hline S49 & 81.7 & 5.7 \\
S50 & 87.8 & 1.7 \\
S51 & 69.1 & 13.5 \\
S52 & 83.0 & 2.2 \\
S53 & 66.1 & 12.2 \\
S54 & 79.6 & 3.0 \\
S55 & 79.1 & 3.0 \\
S56 & 77.4 & 4.8 \\
S57 & 86.5 & 2.6 \\
S58 & 87.0 & 2.2 \\
\hline
\end{tabular}

There were ten strategy statements in strategy of Socio-Cultural Imperatives. Data showed that some of those strategies were highly supported by respondents and others were not given priority. 
The mathematical ranking of distinction ( 80 percent and above), as the outstanding ranking, has been taken as the basis of marking prominent strategies. Following this benchmark, five of the statements have scored more than 80 percent.

Those statements in highest priorities are as follows: Develop curriculum such that students can understand societal issues and social implication of technology, Promote public understanding of engineering and technology, Make efforts in the application of engineering and technology for poverty eradication developing traditional technology, Establish cross cultural harmony and inter-university and institutional cooperation, including fellowships, Make periodic campaigns to establish status and social image of the engineer in the community, etc. 
Infrastructure Strategy

\begin{tabular}{ccc}
\hline Items & High percent & Low percent \\
\hline S59 & 91.3 & 2.2 \\
S60 & 87.4 & 2.2 \\
S61 & 93.5 & 2.2 \\
S62 & 84.8 & 1.7 \\
S63 & 88.3 & 1.7 \\
S64 & 88.7 & 0.4 \\
S65 & 90.0 & 1.3 \\
S66 & 93.9 & 0.4 \\
S67 & 92.2 & 1.3 \\
S68 & 93.5 & 0.9 \\
S69 & 83.5 & 1.7 \\
\hline
\end{tabular}

There were eleven strategy statements in strategy of infrastructures. Data showed that all of those strategies were highly supported by respondents. The mathematical ranking of distinction ( 80 percent and above), as the outstanding ranking, has been taken as the basis of marking prominent strategies. Following this benchmark, all of the eleven statements have scored more than 80 percent. Six statements scored more than 90 percent.

Those statements in highest priorities are as follows: Develop functional electronic network with national \& international reputed institution's libraries, Establish monitoring \& evaluation unit for physical and academic infrastructure \& their quality. Ensure renovation of laboratory instruments, Ensure sufficient text books, reference books \& other extra curricular books, journals, newspaper \& magazine documentation centre, etc. in library and also update and replace them regularly, Ensure physical facilities, equipment and tools used in the program and be of the quality and type needed to training to meet the program goals and performance objectives, ensure that facilities and equipment shall effectively accommodate the number of students, instructors, support staff and program objectives, Ensure copy, documentation and database facilities in the library, Develop Infrastructures in accordance with the new paradigm in engineering education, Prepare a data base of all infrastructures and conduct periodic repair and maintenance, Ensure that there are in sufficient quantity and quality of critical infrastructures to meet the instructional objectives and needs of the academic program, Strengthen and/or replace outmoded infrastructures, ensure Infrastructures to reflect current technologies and applications, Provide grant, soft loan, aid \& donation for infrastructure development \& quality improvement, etc. 
Strategy for Curriculum

\begin{tabular}{ccc}
\hline Items & High percent & Low percent \\
\hline S70 & 80.4 & 7.4 \\
S71 & 92.6 & 2.6 \\
S72 & 88.3 & 1.3 \\
S73 & 87.4 & 1.3 \\
S74 & 77.0 & 5.7 \\
S75 & 86.5 & 1.3 \\
S76 & 85.7 & 1.7 \\
S77 & 90.4 & 1.3 \\
S78 & 90.9 & 0.9 \\
S79 & 82.2 & 3.0 \\
S80 & 87.0 & 1.3 \\
S81 & 89.1 & 1.7 \\
S82 & 90.0 & 0.8 \\
S83 & 92.6 & 0.4 \\
S84 & 81.3 & 3.0 \\
S85 & 87.8 & 1.3 \\
S86 & 90.4 & 1.3 \\
S87 & 83.5 & 1.3 \\
S88 & 91.7 & 0.9 \\
S89 & 85.7 & 0.9 \\
\hline
\end{tabular}

There were twenty strategy statements in strategy of curriculum. Data showed that some of those strategies were highly supported by respondents and others were given less priority. The mathematical ranking of distinction ( 80 percent and above), as the outstanding ranking, has been taken as the basis of marking prominent strategies. Following this benchmark, nineteen of the statements have scored more than 80 percent. Seven statements scored more than 90 percent.

Those statements in highest priorities are as follows: Initiate curriculum reform synchronized with global courses and schedules, Conduct review of failure rate in all regular exams, identify causes and apply corrective measures, Ensure technology development in a socially beneficial way/direction by updating prevailing technology and introducing new technology in the institution, Initiate for regional agreements between educational institutions and insure conformity of Nepalese engineering degree, Develop national norms and standard for engineering education (academic degree and engineering colleges) and ensure its effective enforcement. Conduct exposure of technical know how and trainings necessary to understand application of new technologies, Ensure frequent and integrated assessment with teaching process, Ensure use of varieties of assessment tools (written and oral test, tutorials, and presentations), and Establish performance based assessment, Conduct review and ensure consistent and rigid academic calendar, Conduct the process of curriculum revision in all level of management (departments, instruction committee, academic council and floor) with up-to-date review and integrating Conceiving - Designing - Implementing - Operating (CDIO) model. Conduct the process of curriculum revision in all level of management (departments, instruction committee, academic council and floor) with up-to-date review and integrating Conceiving Designing - Implementing - Operating (CDIO) model, Preserve rigor and breadth of coverage in the curriculum of every discipline based on market needs, Initiate for continuing education and 
lifelong learning through professional organizations. Ensure the Sequence of curriculum organization, such that it leads students to; entry level employment, job advancement, entrepreneurship, education and training, personal use etc. Start implementing quality assurance scheme and complete the first cycle of evaluation within a year in all departments leading to accreditation in short-term period (5years), Conduct regular peer-review for new engineering institutions and activities for the accreditation of engineering qualifications establishing substantial equivalence, Develop classroom delivery developing web-based learning in engineering education, Initiate for the conformity of ISO 9000 standards quality of engineering education, Conduct review of the process of Exams making it objective. Ensure uniformity in the basis of entry eligibility (eligibility criteria should be Physical group in pre-engineering level $(+2 /$ I.Sc.)) in higher engineering education (B.E. Level), etc.

Job-Market Strategy

\begin{tabular}{ccc}
\hline Items & High percent & Low percent \\
\hline S90 & 93.5 & 1.3 \\
S91 & 93.0 & 1.3 \\
S92 & 93.9 & 0.4 \\
S93 & 93.9 & 0.9 \\
S94 & 85.7 & 2.2 \\
S95 & 93.9 & 1.3 \\
S96 & 92.2 & 1.3 \\
S97 & 86.5 & 3.9 \\
S98 & 91.7 & 0.4 \\
S99 & 93.9 & 1.7 \\
\hline
\end{tabular}

There were ten strategy statements in strategy of job-market. Data showed that all of those strategies were highly supported by respondents. The mathematical ranking of distinction $(80$ percent and above), as the outstanding ranking, has been taken as the basis of marking prominent strategies. Following this benchmark, all of the statements have scored more than 80 percent. Eight statements scored more than 90 percent.

Those statements in highest priorities are as follows: Ensure quality academic performance; establish periodic review and monitoring of the academic performance, Conduct research works by establishing Research \& Development centres and identify the critical and conventional areas of jobs thus canalizing necessary human resources, Conduct internships/ on-the-job-training as a practical learning in engineering education, Encourage effective networking and exchange programs with other reputed academic institution within the region and abroad, organize exposure of faculties in different industries, Establish industry - academic institute collaboration for need based research, Develop institution to produce the quality of human resource as demanded by global market, changing needs of society and as per the requirements of the technology development, Develop market relevance courses in academic programs with sufficient contribution on manner and values, Ensure regular and realistic market feedback as an input for course design, Establish global connections and review the market trends thus procuring necessary human resources in global market, Ensure academic decentralization in institution's administrative structure to response the market demand, Strengthen private public partnerships for assessment of the academic performance of students and market response of their performances. 


\section{Conclusions}

The mean values of the rating on financing strategy were similar and in the lower range of the faculty $\&$ student and slightly higher of the employer \& policy makers. The mean values of all respondents except student were in the similar range and of the student in the slightly lower range on strategy for faculties and their role. The mean values of the rating of all the respondents were similar and in the lower range on equity and access strategy. The mean values of rating of all the respondents were in the same range on management and institutional development strategy. The strategy for students' role was marked slightly higher by employer and lower by policy makers. The strategy for socio-cultural imperative was more emphasized by employer and marked in the higher side compare to other respondents. All the respondents rated in the similar range on the infrastructure strategy. The mean values for strategy for curriculum and assessment system were very high indicating high emphasis by all the respondents. Employers have marked still higher compare to other respondents. The mean value of rating of policy makers was higher compare to the values of other respondents on market strategy.

However, the deviations of opinions of the respondents were not substantial in all strategy categories, There were small differences of opinions between respondents in some individual statements. Faculties rated slightly higher on S35. Students rated higher on S43. Faculties rated higher on S46. Employer rated higher on S53. Employer rated higher on S94. Faculties rated higher on S95.

Despite the fact that the respondents marked all the statements as highly considerable, the outstanding statements 20 percent from above have been marked as most prominent statements in all categories as follows;

The prominent statements in category-financing are, more investment for supporting research and innovation and new educational technologies, and efficient utilization of available human, financial and material resources.

The prominent statements in category-financing are, allocating appropriate budget for research and innovation, and allocating appropriate budget for new technologies.

The prominent statements in category-faculties and their role are, starting and establishing dynamic teaching and research process in higher engineering education, and establishing system of continuing professional development of faculties, supporting and encouraging participation of faculties in regional conferences, workshops and electronic conferences, providing internet facilities and encouraging publications over internet.

The prominent statements in category-equity and access strategies are, encouraging government for financial assistance, manage financial assistance by reliable organizations to needy students, develop financing model with bank loan facilities and target subsidies to poor and needy students with a focus on reducing inequalities, discouraging inefficiencies and encouraging incentives for positive innovation and generation of additional resources, and starting support programs for students from marginalized areas in pre-engineering level for building their capacity to compete in entry level of higher engineering education.

The prominent statements in category-management strategies are, conducting periodic meetings of all departments, committees and centres and arrange discussions on strategies, challenges and programs, and developing norms and regulations to guide the behaviours of the management, faculties and staffs and avoid ad-hoc decisions. 
The prominent statements in category-students and their activities are, encouraging academic and professional key skills, such as; publications of journals, new-letters web etc, interpersonal team working, presentation skill and ICT skills, and orienting students for; well prepared to be leading engineers, as well as researchers, with a clear understanding of the strategic value of their area.

The prominent statements in category-socio-cultural imperatives are, developing curriculum such that students can understand societal strategies and social implication of technology, and promoting public understanding of engineering and technology.

The prominent statements in category-infrastructure strategies are, developing functional electronic network with national \& international reputed institution's libraries, and establishing monitoring \& evaluating unit for physical and academic infrastructure \& their quality.

The prominent statements in category-curriculum strategies are, initiating curriculum reform synchronized with global courses and schedules, conducting review of failure rate in all regular exam, identify causes and apply corrective measures, ensuring technology development in a socially beneficial way/direction by updating prevailing technology and introducing new technology in the institution, and initiate for regional agreements between educational institutions and insure conformity of Nepalese engineering degree.

The prominent statements in category-job-market strategies are, ensuring quality academic performance, establishing periodic review and monitoring of the academic performance, and conducting research works by establishing Research \& Development centres and identifying the critical and conventional areas of jobs thus canalizing necessary human resources.

\section{REFERENCES}

[1] IOE, (2005), Annual report of the Institute of Engineering. Tribhuvan University, Pulchowk, Lalitpur

[2] Pahari, B.R. (2008, August). Reform Strategies for Quality of Engineering higher Education in Nepal, a Ph.D. Dissertation presented in the Kathmandu University, Kathmandu

[3] Paudel, R.K. (2006, January). Priorities and strategies of engineering education: national and global perspective, (a seminar paper presented in a seminar organised in Institute of engineering), Kathmandu

[4] Shrestha, P.B. (2006, January). Quality assurance strategy, policy framework and guidelines for the institutionalisation of a quality assurance system in the engineering education and training sector in Nepal, (A comment paper presented in the seminar organised in IOE), Kathmandu

[5] University Grant Commission [UGC], (2004). Annual Report-2003/2004 of University Grant Commission, Kathmandu 